\title{
Erratum to: Kurtosis and skewness assessments of solid lung nodule density histograms: differentiating malignant from benign nodules on $\mathbf{C T}$
}

\author{
Ayano Kamiya $\cdot$ Sadayuki Murayama $\cdot$ \\ Hisashi Kamiya • Tsuneo Yamashiro • \\ Yasuji Oshiro $\cdot$ Nobuyuki Tanaka
}

Published online: 28 February 2014

(C) Japan Radiological Society 2014

\section{Erratum to: Jpn J Radiol (2014) 32(1):14-21}

\section{DOI 10.1007/s11604-013-0264-y}

Unfortunately, errors appeared in Table 2 of the abovementioned article. In the column headed "Kurtosis, Mean \pm SD", in the entries for "All nodules" the values for "Malignant $(n=72)$ " and "Benign $(n=21)$ " are reversed. They should be " $1.10 \pm 1.77$ " for malignant nodules, and " $0.42 \pm 1.75$ " for benign nodules, respectively.

The online version of the original article can be found under doi:10.1007/s11604-013-0264-y.

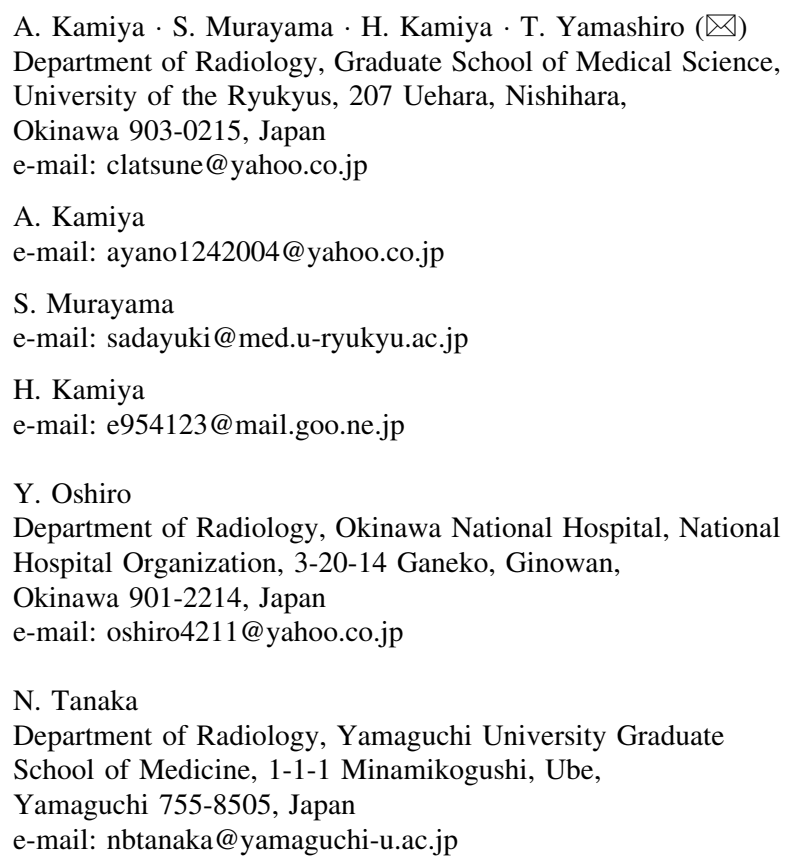

